\title{
METHODOLOGICAL APPROACH TO THE HUMAN RESOURCE MANAGEMENT IN VIRTUAL ORGANIZATIONS
}

\author{
Masuma Mammadova \\ Institute of Information Technology of the National Academy of Sciences of Azerbaijan \\ 9 B. Vahabzada str., Baku, Azerbaijan, AZ1141 \\ Zarifa Jabrayilova \\ Institute of Information Technology of the National Academy of Sciences of Azerbaijan \\ 9 B. Vahabzada str., Baku, Azerbaijan, AZ1141
}

\begin{abstract}
In each organization, the goal of human resource management (HRM) is to form, employ and develop human resources. The massive spread of Internet technologies and the globalization of the economy in the late twentieth century have allowed the enterprises to form a temporary partnership, and subsequently have led to the formation and expansion of virtual organizations (VO) by establishing these relationships over the Internet. Unquestionably, the success of VO depends on appropriate organization of HRM and selection, deployment, socialization, motivation and evaluation of employees and partners. In this regard, this paper analyzes the features of HRM in VO and proposes methods for the recruitment and assessment of the performance of virtual employees (contractors).

The article analyzes the specific features of HRM in VO. The issues of HRM in VT are characterized as decision-making in fuzzy environment. Based on the peer comparison of expert estimates for the alternatives, including on the hierarchical analysis method, detection of the contradictions in the expert estimates and multiplicative aggregation methods, a decision making technique is proposed for the recruitment of the employees.

Assessment of the virtual employees' performance to achieve overall objective of the organization is formulated as a decision-making process in distributed environment and appropriate decision-making methods are proposed.

The proposed approach is a methodological framework for decision support for human resources management in virtual organizations. This system can support more objective and scientifically justified decision-making on presented task. It can also enable VO to be more "reliable" in relation to the "trust" component for the formation of VO, which is the key point for the increase of the effectiveness of VO.
\end{abstract}

Keywords: virtual organization, human resources management, fuzzy environment, virtual employees, decision-making methods in distributed environment.

\section{Introduction}

The massive spread of Internet technologies and the globalization of the economy in the late twentieth century have allowed the enterprises to form a temporary partnership, and subsequently have led to the formation and expansion of virtual organizations (VO) by establishing such links over the Internet [1-3]. Due to the frequent change of the market requirements, separate organizations are attempting to achieve common goals by paying these requirements and involving companies-partners with necessary skills and competence. This, in turn, has created favorable condition for the unification of organizations and various legal and geographically independent structures in a new corporate virtual model. Consequently, virtual firms, virtual corporations, virtual department, virtual groups, and virtual working spectrum have enlarged in the sphere of employment. The process of virtualization of organizations has changed the social-labor relations and traditional governance mechanisms in the labor sphere, which has led to the change of staffing functions, the content of labor contracts and the change of traditional institutions for information collection.

The relations between VO members usually occur through a computer network; and the managers coordinate and manage foreign affairs through computer network connections [4, 5]. From this point of view, they are flexible organizations. The flexibility entails multiple versions of implementation, flexible work schedule, incomplete working day, job sharing, and freelance work. One of the most important principles here is to respond quickly to both internal and external changes. 
At present, $\mathrm{VO}$ in the business sector is accepted as a firm that holds the external contractors to fulfill its core functions. In some cases, VOs are created from independent organizations that share resources and skills to achieve the goals.

Unquestionably, the success of VO depends on appropriate organization of human resources management (HRM) and selection, deployment, socialization, motivation and evaluation of employees and partners. In this regard, this paper analyzes the features of HRM in VO and proposes methods for the recruitment and assessment of the performance of virtual employees (contractors).

\section{Features of HRM in VO}

In each organization, the goal of HRM is to form, employ and develop human resources.

Formation of human resources in VO is defined by selecting and recruiting staff or partners to VO. It urges the following new requirements for managers and employers [6, 7]:

- involving employees or professionals who are accustomed to innovative technologies and ready to work in more flexible virtual business environment unlike the traditional one;

- determining the characteristics of next generation employees (shaping reserves) without considering geographical parameters, space and time;

- dentifying more accurate and flexible method for communication with employees;

- adopting and using new technological priorities.

The use of human resources in VO envisages the evaluation, rewarding, and motivation of each employee in achieving efficient production and common outcome.

The development of human resources in VO should comprise mastering new trends in the field of modern information technology, as well as regularly tracking and training new ideas and progress.

The concept of HRM is constituted by the requirements put forward to employees in VO and specificity of mutual relations in the course of problem solution. This concept is regarded as a set of mechanisms, principles, forms and methods that impact the formation, development and use of human resources of the organization, and the success of VO depends on their proper organization, i. e., on the managers. They are responsible for the management and regulation of the environment to achieve the expected goals [5]. Therefore, HR-Manager in VO should consider the independence and self-organization of employees to ensure the flexibility by controlling and coordinating their performance [1].

HRM managers in VO are required to work in a flexible and innovative environment and to update management system through non-standard approaches and solutions with the presence of changing organizational issues. From this point of view, the work of VO managers can be considered innovative, which in turn promotes the development of decision support systems referring to intelligent technology.

The characteristics of VO may include dynamics, informal communication, multidisciplinary teams, uncertainty of organizational boundaries, objective-oriented, working from home, lack of visible organizational structure, reference to mental work of integrated employees, etc., which define the following specific features of HRM issues:

- incomplete and inaccurate information provided to the decision-maker about the capabilities of companies, co-workers and partners included into VO and about their performance;

- establishment of relationships of VO's operation on the basis of trust factor, and consequently, dependence on the results of the operation on individual and psychological aspects;

- dependence of general corporate outcome on local results, and the latter's inaccuracies and uncertainty;

- dependence of the results of VO HRM issues on quantitative and qualitative aspects, and the emergence of uncertainties arising from the time factor;

- uncertainty emerged in the assessment of the performance of a virtual employee or partner, etc.

These aspects characterize HRM issues in VO, particularly selection and evaluation of employees as poorly structured and hard-to-formalize issues, and necessitate the use of fuzzy logic theory [7-10]. 


\section{Modeling the recruitment of the employees at VO}

To establish innovative teams, VO sets out specific and vital requirements for selected employees. The requirements include $[1,6]$ :

- level of intelligence determined by the analytical, abstract, and systematic thinking ability of the employee, "confidence in intellect" in problem solving;

- professionalism, familiarization with the work;

- responsibility and flexibility, knowledge of organizational procedures, effectively communicative and readiness for adaptation;

- ability to work in team and to focus individual goals on achieving overall results.

Decision-making in such environment makes it necessary to use the methods of formalization of expert knowledge as the formalism of incomplete and inaccurate information processing.

Selection of partners is crucial for the formation of $\mathrm{VO}$, however, very little attention is paid to the decision-making methods in solving this issue. Let's take a brief look at the analysis of several methods devoted to this problem.

The process of selection of partners should be viewed not as a mathematical modeling issue but as a matter of multi-criteria decision-making. The incompleteness and inaccuracy of the information possessed by the decision-maker about the capabilities and productivity of the partners is reflected in the uncertainty of the relationship of the first ones. The consideration of such uncertainty problem in the assessment confirms of the urgency of the use of hierarchical analysis methods (HAM) and fuzzy numbers obtained by referring to the statements' comparison [11]. [9, 10] reviews the issue of selecting the partners based on such approach. [9] uses the value, quality, financial stability, customer service as an evaluation criteria, while [10] proposes a method for determining the proximity of the ideal solution based on HRM for a quick and objective choice of partners in solving certain projects. The proposed approach is solved by referring to additive aggregation [12, 13], which enables the participation of any alternative in the recruitment even though it (alternative) is equal to zero, and even allows selecting the best alternative.

Such approach can be used to hire employees in traditional organizations, and the compensation of the unsatisfied criteria can be attributed to other criteria (or employee's training in organizational activities may be envisaged) [14]. However, in the VO, employees are involved in the implementation of a specific short-term project $[2,10,15]$ for each of these requirements are to be satisfied, and this requires a reference to the multiplicative aggregation method for selecting the best alternative and ranking the alternatives.

On the other hand, it is also crucial to check whether the expert estimates are agreed upon in the decision-making process when referring to the comparison of the expert statements. Hence, in this article, the issue of selecting employees and partners at VO is reduced to the multi-criteria decision issue referring to the comparison of expert statements to evaluate the employees and partners, and to determine HAM and the methods of detecting the contradictions in expert evaluations, and decision-making method is proposed by referring to multiplicative aggregation methods for choosing the best alternative.

\section{Technique for selection of employees at VO}

The technique for the selection of employees at VO is offered in the following stages:

1) formulation of problem, alternatives, criteria and goals;

2) assessment of criterion;

3) determining the importance ratios of criterion;

4) detection of contradictions in the expert statements concerning the assessment of criterion;

5) assessment of alternatives;

6) selection of alternative with the highest value.

HAM-based decision making process has a hierarchical structure that has elements on the levels, and each level has a number of crucial elements (Fig. 1): 
- upper level of the hierarchy implies the general purpose and is indicated by R;

- next level of the hierarchy implies the criteria and is indicated by

$$
\mathrm{K}=\left\{\mathrm{k}_{\mathrm{j}}, \mathrm{j}=\overline{1, \mathrm{~m}}\right\}
$$

- lower level of the hierarchy displays all possible alternatives:

$$
X=\left\{x_{i}, i=\overline{1, n}\right\} .
$$

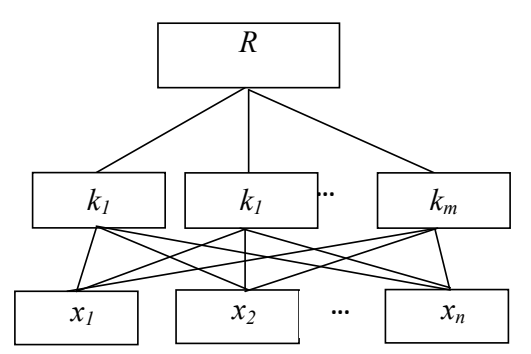

Fig. 1. Hierarchical structure of the selection of employees at VO

The decision-maker (expert) expresses his/her attitude in linguistic values that indicate the peer comparisons of priorities (second level - criteria, and third level - alternatives) for each level. Comparison of the second level of priorities (criteria) defines the weight value of the criteria $\mathrm{w}_{\mathrm{j}}$, $\mathrm{j}=\overline{1, \mathrm{~m}}$, and the comparison of the third level of priority (alternatives) defines their fuzzy values $r_{k j}\left(x_{i}\right), i=\overline{1, n}, j=\overline{1, m}$. These values represent the priority of the alternative $x_{i}$ for criteria $k_{j}$. The common purpose values of the alternatives are determined by referring to multiplicative aggregation based on the following formula $[13,16]$ :

$$
R_{i}=\prod_{j=1}^{m} r_{k_{j}}\left(x_{i}\right)^{w_{j}} .
$$

Here, $R_{i}, i=\overline{1, n}$ is a fuzzy number used for the ranking and selection of the alternatives and expresses the priority of each alternative for a common purpose.

The main issue when using HAM is a peer comparison of the priorities at the same level and finding a relative importance factor in relation to each other. Decision-making is carried out in the following stages and solved by selecting the best alternative:

- obtaining the statements of the peer comparison of the criteria and establishing peer comparison tables by referring to [11], and determining relative importance ratios $w_{j}, j=\overline{1, m}$;

- detection of contradictions in expert statements;

- peer comparison of the alternatives for each criterion, formation of comparison tables;

- calculation of the priority ratios $R_{i}, i=\overline{1, n}$ of the alternatives based on the formula (1).

- selecting the alternative with the highest value: making decision on selecting a partner and

$$
\mathrm{R}^{*}=\max \left\{\mathrm{R}_{\mathrm{i}}, \mathrm{i}=\overline{1, \mathrm{n}}\right\} \text {. }
$$

To find the importance ratios of the priorities on the basis of their peer comparisons, 9-grade Saaty schedule is used [11] (Table 1).

If the number of indicators is equal to $\mathrm{m}$, the relationship matrix is set knowing the relations of number $\mathrm{m}-1$ implying their peer comparison, and the matrix has the features of diagonally $\left(\mathrm{K}_{\mathrm{jj}}=1, \mathrm{j}=\overline{1, \mathrm{~m}}\right)$, symmetry $\left.\mathrm{K}_{\mathrm{tj}}=\mathrm{K}_{\mathrm{jt}}{ }^{-1}\right)$ and transitivity $\left(\mathrm{K}_{\mathrm{tg}} \cdot \mathrm{K}_{\mathrm{gj}}=\mathrm{K}_{\mathrm{tj}}\right)$. Importance ratios of the matrix-based criteria are based on the following formula [11]:

$$
\mathrm{w}_{\mathrm{t}}=\sum_{\mathrm{j}=1}^{\mathrm{m}} \mathrm{k}_{\mathrm{tj}} \times\left(\sum_{\mathrm{t}=1}^{\mathrm{m}} \sum_{\mathrm{j}=1}^{\mathrm{m}} \mathrm{k}_{\mathrm{tj}}\right)^{-1} .
$$


Table 1

9-scale Saaty table of relative priority degrees of criteria

\begin{tabular}{cc}
\hline Value & Linguistic expression \\
\hline 1 & Criteria $K_{l}$ does not exceed the criteria $K_{2}$ \\
3 & Criteria $K_{l}$ fairly exceeds the criteria $K_{2}$ \\
5 & Criteria $K_{l}$ noticeablyexceeds the criteria $K_{2}$ \\
7 & Criteria $K_{l}$ significantly exceeds the criteria $K_{2}$ \\
9 & Criteria $K_{l}$ exceeds the criteria $K_{2}$ several times \\
$2,4,6,8$ & intermediate ideas among listed degrees
\end{tabular}

The maximum specific value of the matrix $\lambda_{\max }$ is calculated based on for verifying that the expert statement is agreed upon the peer comparison of the priorities. For this purpose, it is referred to the method of rough estimation of consistency, and the matrix of comparisons is multiplied to the relative importance ratios of criteria [11]. A further vector is obtained through dividing the first component of the new matrix by the importance of the first criterion, and the second component by the importance of the second criterion, and so forth. $\lambda_{\max }$ (maximum or head-specific value) is obtained by dividing the sum of the components by the number of the components of this vector. The closer the value of $\lambda_{\max }$ to $\mathrm{n}$, the more agreed the result is. The deviation from the Consistency index $(C I)$ of the agreement is designated by the formula below as follows:

$$
\mathrm{CI}=\left(\lambda_{\max }-\mathrm{m}\right) /(\mathrm{m}-1) .
$$

Diving consistency index of the matrix by the appropriate Random Consistency $(R C)$ limit allows the assignment of Consistency Relation (CR):

$$
\mathrm{CR}=\mathrm{CI} / \mathrm{RC} \text {. }
$$

According to [11] random consistency $\mathrm{RC}=0.58$ for matrix $\mathrm{m}=3 ; \mathrm{RC}=0.90$ for $\mathrm{m}=4 ; \mathrm{RC}=1.12$ for $\mathrm{m}=5 ; \mathrm{RC}=1.24$ for $\mathrm{m}=6$, and so forth.

When $\mathrm{CR} \leq 0,1$, consistency limit is considered to be acceptable, otherwise, the expert assessment is required to be reviewed again.

Based on the proposed approach, in [7], selection of virtual employees is realized, and the followings are accepted as the selection criteria: $\mathrm{k}_{1}$ - denotes the level of intelligence, $\mathrm{k}_{2}$-professionalism, $\mathrm{k}_{3}-$ responsibility, $\mathrm{k}_{4}-$ team work ability.

\section{Use and assessment of human resources in VO}

Performance of VO's staff is "short-term", and therefore, the lack of mechanisms to measure each employee's contribution to the achievement of the overall objective and to stimulate "shortterm" activities is one of the key issues to be solved in $\mathrm{VO}[5,6]$.

The use of human resources in VO is accompanied by a variety of goals. Since VO is a temporary organization consisting of different employees (groups, companies) performing independent functions and different objectives for problem solution, unsurprisingly their interests in achieving a common goal will be different, and assessing the outcome of each employee's performance is topical.

Assessment of the performance of virtual groups (or corporations) in VO depends on the nature of their work. Thus, assessment of the work of virtual groups performing the same function can be essentially characterized as the assessment of the objects that are categorized by the same criteria and functioning in a fragmented environment. If virtual groups perform different functions, their activities can be characterized as the assessment of the objects that are categorized by the same criteria and functioning in a fragmented environment. 
Abovementioned determine the dependence of the overall corporate outcome on the local results and the latter's inaccuracy and uncertainty. From this point of view, the evaluation of employees in VO includes the following aspects as a matter of decision-making in a distributed environment $[17,18]$ :

1) multitude, contradiction and incompleteness of knowledge and data about the object (employee's performance);

2) information necessary for the mathematical description of the object (employee's performance) in the form of individual knowledge of the specialist-experts, and the lack of qualitative character of this information, and therefore the high complexity of the formalization of the object's description;

3) non-homogeneity of information about the object (expert assessment, functional interdependence of parameters, etc.);

4) importance of taking into account the distributed knowledge about the object in terms of both geographical and functional distribution;

5) excessive number of factors describing the object, complexity resulting from the their restricted variation boundaries.

Hence, VO is characterized as a system of fragmented subsystems, i. e., VO consists of several groups of identically organized network nodes. Each of these groups has individual objective, however does not have sufficient information and resources to solve the common problem [17, 18]. The process of decision-making based on subsystems is implemented by stages and sections. One of the main criteria for structuring the process of decision-making is to describe it as separate decisions on fragments (local decisions). In this case, the final decision is made based on the analysis of individual decisions. For a number of situations, the principle of superposition for a final decision is ensured. According to this principle, if the decision-making process is split up into a number of sub-processes on the fragments, then the best decision will be found within the best decisions found on the fragments. However, this principle is not always ensured for all fragmented cases.

Depending on the nature of the function performed by the virtual groups, three types of distribution are distinguished:

1) virtual groups are performing the same functions - horizontal distribution;

2) virtual groups are performing the functions of different characteristics - vertical distribution;

3) virtual groups are performing the functions of blended characteristic - blended distribution.

The physical fragmentation of the necessary information depends on the criteria that characterize the alternatives (employees) and the relations with the sub-criteria. Thus, the assessment of employees' performance in VO consisting of subsystems is solved by reducing the task to the decision making task in a distributed environment.

\section{Assessment methods of employees' performance in VO}

Using the fuzzy logic apparatus, the methods are offered for decision-making in a distributed environment for the assessment of employees' performance in accordance with their horizontal and vertical distribution in VO and a fuzzy relay model is used for this purpose [17, 18]. According to fuzzy relational model of representation of knowledge, if $X=\left\{x_{i}, i=\overline{1, n}\right\}-$ a set of alternatives which are subject to an estimation and ranging, and $K=\left\{\mathrm{k}_{\mathrm{j}}, \mathrm{j}=\overline{1, \mathrm{~m}}\right\}-$ a set of criteria characterizing these alternatives then degree of satisfaction of alternative $\mathrm{x}_{\mathrm{i}}$ to criterion $\mathrm{k}_{\mathrm{j}}$ is represented by membership function $\phi_{\mathrm{k}_{\mathrm{j}}}\left(\mathrm{x}_{\mathrm{i}}\right) \rightarrow[0,1]: \phi_{\mathrm{k}_{\mathrm{j}}}\left(\mathrm{x}_{\mathrm{i}}\right): \mathrm{X} \times \mathrm{K} \rightarrow[0,1]$.

Decision-making methods in distributed environments. The following conditions in horizontal distribution of Virtual Groups are ensured:

$$
X=\bigcup_{g=1}^{G} X_{i g},
$$

where $X$ - a set of alternatives, $X_{i g}$-alternatives in the $g$-th fragment (sub-system) and $X_{\mathrm{ig}} \cap X_{\mathrm{ij}}=\varnothing$ and 


$$
\mathrm{K}_{\mathrm{g}} \cap \mathrm{K}_{\mathrm{j}}=\mathrm{K}_{\mathrm{g}}=\mathrm{K}_{\mathrm{j}}=\mathrm{K}
$$

for $\forall \mathrm{g} \neq \mathrm{j}$.

That is, the alternatives distributed by fragments are characterized by the same criteria $[6,7]$. Criteria have a hierarchical structure and different weight coefficients, i. e.:

$$
\mathrm{K}=\left\{\mathrm{K}_{\mathrm{m}}, \mathrm{m}=\overline{1, \mathrm{M}}\right\},
$$

$\mathrm{w}_{1}, \mathrm{w}_{2}, \ldots, \mathrm{w}_{\mathrm{T}}$ - the relative importance ratios of criteria $\mathrm{K}_{\mathrm{m}}, \mathrm{m}=\overline{1, \mathrm{M}}$.

$$
\mathrm{K}_{\mathrm{m}}=\left\{\mathrm{k}_{\mathrm{mt}}, \mathrm{t}=\overline{1, \mathrm{~T}}\right\}
$$

and $\mathrm{w}_{\mathrm{m} 1}, \mathrm{w}_{\mathrm{m} 2}, \ldots, \mathrm{w}_{\mathrm{mT}}-$ the relative importance ratios of sub-criteria characterizing the criterion $\mathrm{K}_{\mathrm{m}}$. Assume that, in each fragment, the membership function of sub-criteria is known:

$$
\left\{\phi_{\mathrm{k}_{\mathrm{m} 1}}\left(\mathrm{x}_{\mathrm{ig}}\right), \phi_{\mathrm{k}_{\mathrm{m} 2}}\left(\mathrm{x}_{\mathrm{ig}}\right), \ldots, \phi_{\mathrm{k}_{\mathrm{mT}}}\left(\mathrm{x}_{\mathrm{ig}}\right)\right\}=\left\{\phi_{\mathrm{k}_{\mathrm{mt}}}\left(\mathrm{x}_{\mathrm{ig}}\right), \mathrm{t}=\overline{1, \mathrm{~T}}\right\} .
$$

Decision making process is performed on the following steps:

1. The membership function of alternatives to the criterion $K_{m}$ in each fragment is defined:

$$
\phi_{\mathrm{K}_{\mathrm{m}}}\left(\mathrm{x}_{\mathrm{ig}}\right)=\sum_{\mathrm{t}=1}^{\mathrm{T}} \mathrm{w}_{\mathrm{mt}} \phi_{\mathrm{k}_{\mathrm{mt}}}\left(\mathrm{x}_{\mathrm{ig}}\right) .
$$

2. The membership function of alternatives to the generalized criterion $K$ in each fragment is defined:

$$
\phi_{\mathrm{K}}\left(\mathrm{x}_{\mathrm{ig}}\right)=\sum_{\mathrm{m}=1}^{\mathrm{M}} \mathrm{w}_{\mathrm{m}} \phi_{\mathrm{Km}}\left(\mathrm{x}_{\mathrm{ig}}\right) .
$$

3. The maximum of alternatives by fragments is selected:

$$
\phi\left(x^{*}\right)=\max \left\{\phi_{\mathrm{K}}\left(\mathrm{x}_{\mathrm{ig}}\right), \mathrm{g}=\overline{1, \mathrm{G}}, \mathrm{i}=\overline{1, \mathrm{~N}}\right\} .
$$

The alternative with the maximum value is the final decision on horizontally distributed virtual groups, and it is found out of set of decisions with the maximum values on fragments, i. e.,

$$
x^{*} \in\left\{x_{\text {ig }}^{*}, g=\overline{1, G}\right\} .
$$

The following conditions are ensured for vertical distribution of virtual groups:

$$
\mathrm{K}=\bigcup_{\mathrm{m}=1}^{\mathrm{M}} \mathrm{K}_{\mathrm{m}},
$$

where $K$ consists of a set of criteria

$$
\mathrm{K}=\left\{\mathrm{K}_{\mathrm{m}}, \mathrm{m}=\overline{1, \mathrm{M}}\right\}
$$

with different importance degree, and $\mathrm{M}$ - the number of fragments (groups).

$$
\mathrm{K}_{\mathrm{m}}=\left\{\mathrm{k}_{\mathrm{mt}}, \mathrm{t}=\overline{1, \mathrm{~T}}\right\}
$$

is a set of sub-criteria with different importance degree in each fragment, and $\mathrm{w}_{\mathrm{m} 1}, \mathrm{w}_{\mathrm{m} 2}, \ldots, \mathrm{w}_{\mathrm{mT}}$ are the relative importance factors of sub-criteria. 
In this case, the following conditions are ensured:

$$
\mathrm{K}_{\mathrm{mg}} \cap \mathrm{K}_{\mathrm{mj}}=\varnothing \text { and } \mathrm{X}_{\mathrm{g}} \cap \mathrm{X}_{\mathrm{j}}=\mathrm{X}_{\mathrm{g}}=\mathrm{X}_{\mathrm{j}}=\mathrm{X}
$$

for $\forall \mathrm{g} \neq \mathrm{j}$.

That is, the same alternatives for vertically distributed VO by fragments are characterized and evaluated by different criteria $[6,7]$. Let's assume that membership function of the alternative $\mathrm{x}_{\mathrm{i}}$ to the sub-criteria in the $\mathrm{m}$-th fragment is known:

$$
\left\{\phi_{\mathrm{k}_{\mathrm{m} 1}}\left(\mathrm{x}_{\mathrm{i}}\right), \phi_{\mathrm{k}_{\mathrm{m} 2}}\left(\mathrm{x}_{\mathrm{i}}\right), \ldots, \phi_{\mathrm{k}_{\mathrm{m} \mathrm{T}}}\left(\mathrm{x}_{\mathrm{i}}\right)\right\}=\left\{\phi_{\mathrm{k}_{\mathrm{mt}}}\left(\mathrm{x}_{\mathrm{i}}\right), \mathrm{t}=\overline{1, \mathrm{~T}}\right\}
$$

The final decision on the employees' performance in the vertically fragmented VO is made as follows:

1. The membership function of alternatives to the criterion $K_{m}$ in each fragment is defined:

$$
\phi_{\mathrm{K}_{\mathrm{m}}}\left(\mathrm{x}_{\mathrm{i}}\right)=\sum_{\mathrm{t}=1}^{\mathrm{T}} \mathrm{w}_{\mathrm{mt}} \phi_{\mathrm{mt}}\left(\mathrm{x}_{\mathrm{i}}\right) .
$$

2. The membership function of alternatives to the generalized criterion is defined:

$$
\phi_{\mathrm{K}}\left(\mathrm{x}_{\mathrm{i}}\right)=\sum_{\mathrm{m}=1}^{\mathrm{M}} \mathrm{w}_{\mathrm{m}} \phi_{\mathrm{K}_{\mathrm{m}}}\left(\mathrm{x}_{\mathrm{i}}\right) .
$$

3. The alternative with the maximum value for the membership function to the generalized criterion $K$ is chosen:

$$
\phi_{\mathrm{K}}\left(\mathrm{x}^{*}\right)=\max \left\{\phi_{\mathrm{K}}\left(\mathrm{x}_{\mathrm{i}}\right), \mathrm{i}=\overline{1, \mathrm{~N}}\right\}
$$

Selected alternative with the maximum value is corresponding to the final decision on the vertical fragments, and this decision may not be from the best decisions, i. e., from the set of fragments

$$
\phi_{\mathrm{Km}}\left(\mathrm{x}^{*}\right)=\max \left\{\phi_{\mathrm{Km}}\left(\mathrm{x}_{\mathrm{i}}\right), \mathrm{i}=\overline{1, \mathrm{~N}}\right\} \text {. }
$$

In an environment where the VO is distributed by blended (both horizontally and vertically) fragments, the decision-making process can be accomplished by referencing to decision-making methods in a vertical distribution environment.

\section{Conclusion}

In VOs, employees are distributed by their locations and there are problems with establishing the contact with them. Moreover, the time of establishing relations, selection of the working language and diversity of cultures are challenging. The proposed approach to the recruitment and assessment of employees' performance in VO provides scientifically substantiated objective decisions and the evaluation (and ranking) of alternatives not only for the final result, but also for each criteria and sub-criteria. Building decision support system based on this methodological approach will also enable building the "data bank" about virtual employees (partners). This, in turn, can be further used as a valuable source for re-recruiting (or not recruiting) the relevant employees to building the innovate groups. It creates favorable condition for more reliable relationship rather than the initial relationships established with the employees based on the "trust" component.

\section{References}

[1] Sankova, L. (2007). HR-management in virtual organizations: problems and prospects. Personnel management. 5. Available at: http://www.top-personal.ru/issue.html?1043 
[2] Camarinha-Matos, L. M., Afsarmanesh, H., Ollus, M. (Eds.) (2005). Virtual Organizations: Systems and Practices. Springer Science \& Business Media, 340. doi: 10.1007/b102339

[3] Nami, M. R. (2008). Virtual Organizations: An Overview. IFIP - The International Federation for Information Processing, 211-219. doi: 10.1007/978-0-387-87685-6_26

[4] Heneman, R. L., Greenberger, D. B. (2002). Human resource management in virtual organizations. Greenwich, Conn: Information Age Pub, 381.

[5] Junyan, D. U. Information Technology in Virtual Enterprise Human Resources Management Application. Available at: http://www.seiofbluemountain.com/upload/product/201010/2010qychzh03a3.pdf

[6] Boljanović, J. D., Dobrijevic, G., Dokovic, F. (2016). Challenges of human resource management in a virtual business environment. International Scientific Conference on ICT and E-Business Related Research, 389-394.

[7] Mammadova, M., Jabrayilova, Z. (2018). Techniques for personnel selection in virtual organization. Problems of Information Technology, 09 (1), 15-24. doi: 10.25045/jpit.v09.i1.02

[8] Zadeh, L. A. (1965). Fuzzy sets. Information and Control, 8 (3), 338-353. doi: 10.1016/s00199958(65)90241-x

[9] Mikhailov, L. (2002). Fuzzy analytical approach to partnership selection in formation of virtual enterprises. Omega, 30 (5), 393-401. doi: 10.1016/s0305-0483(02)00052-x

[10] Polyantchikov, I., Shevtshenko, E., Karaulova, T., Kangilaski, T., Camarinha-Matos, L. M. (2017). Virtual enterprise formation in the context of a sustainable partner network. Industrial Management \& Data Systems, 117 (7), 1446-1468. doi: 10.1108/imds-07-2016-0274

[11] Saati, T. L. (1993). Decision-making. Hierarchical analysis method. Moscow: Radio and Communication, 320 .

[12] Larichev, O. I. (2002). Theory and methods of decision making, and chronicle of events in magical countries. Moscow: Logos, 392.

[13] Neuman, D. V., Morgenstern, O. (1970). Game theory and economic behavior. Moscow: Science 708.

[14] Mammadova, M. H., Djabrailova, Z. G. (2018). Decision-Making Support in Human Resource Management Based on Multi-Objective Optimization. TWMS Journal of Pure and Applied Mathematics, 9 (1), 52-72.

[15] Samdantsoodol, A., Cang, S., Yu, H., Eardley, A., Buyantsogt, A. (2017). Predicting the relationships between virtual enterprises and agility in supply chains. Expert Systems with Applications, 84, 58-73. doi: 10.1016/j.eswa.2017.04.037

[16] Mammadova, M. H., Jabrayilova, Z. Q., Mammadzada, F. R. (2016). Fuzzy Multi-scenario Approach to Decision-Making Support in Human Resource Management. Studies in Fuzziness and Soft Computing, 19-36. doi: 10.1007/978-3-319-32229-2_3

[17] Mammadova, M. H., Jabrayilova, Z. G. (2005). Decision making in the management of hard-to-formalize systems. Automation and Computer Engineering, 6, 33-39.

[18] Mammadova, M. H. (1997). Decision-making based on knowledge bases with fuzzy relational structure. Baku: Elm, 296. 